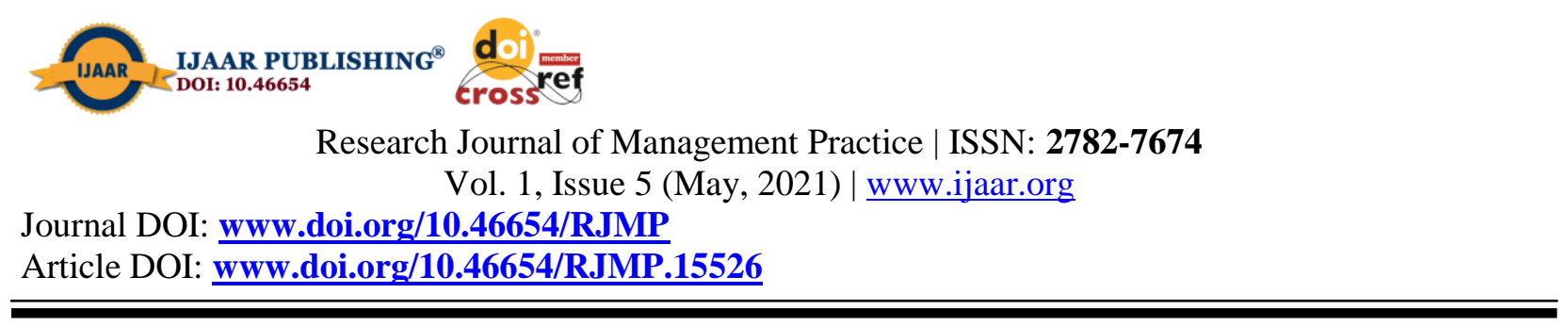

\title{
COMMUNICATION AND ORGANIZATIONAL CONFLICT MANAGEMENT
}

\author{
ONASANYA OPEYEMI O. MSc, MBA, PGDFM, M.hed \\ Email: opeyemionasanya@gmail.com \\ Ph.D. STUDENT, AFE BABALOLA UNIVERSITY, COLLEGE OF SOCIAL AND \\ MANAGEMENT SCIENCES.
}

\begin{abstract}
Conflict is a situation that occurs when two people did not come to agree with each other, having varying opinion about a subject matter. Wherever human beings are congregated or made to co-exist with one another, conflict is inevitable. This is because each individual emanated from different background, family cycle, educational background, class, race etc. Therefore we are meant to think differently, observe things differently and also react to issues differently. The ability of the manager to manage this conflict well to the advantage of the organization is our area of focus.
\end{abstract}

Key words: Organizational Conflict, Organizational Communication, Conflict Management 
Introduction: A condition at the workplace that includes the misunderstanding or miscommunication among the employees of the organization due to the actual or the perceived contradiction of the needs, interests and values may be referred to as the organizational conflict. As a matter of fact, everywhere humans are gathered, as long as it is not the same person thinking on behalf of others, there is bound to be conflict. Even among human body parts, sometime the teeth injures the tongue, among children of the same parent, conflict occurs. So it will be right to say that organizational conflict are inevitable and should be prepared for like any other important thing in organizational management. There are several types of conflicts that may arise within an organization, when they are well communicated and managed it becomes functional to the organization, but if otherwise, it becomes dysfunctional to the organization.

\section{Organizational Conflict:}

An organization is a legal entity having different units coming together to utilize available resources in other to achieve the goals and objectives of the organization. Interaction between the different units in order to perform task and everyone trying to lay hands on the limited available resources can lead to conflict. Conflict is mostly seen as difficult, uncomfortable, and a source of problem, but if an organization must experience change in order to move forward, then conflict is a stimulant. Conflict is presumed to be "a consequence or at least evidence of a stoppage, breakdown, error, or deterioration in communication" (Ruben 1978: 205).

\section{Organizational Communication:}

This is the sending and receiving of messages among interrelated individuals within a particular environment or setting to achieve individual and common goals. Organizational communication is highly contextual and culturally dependent. Individuals in organizations transmit messages through face-to-face, written, and mediated channels (Adu-Oppong \& Agyin-Birikorang, 2014). Organizational communication is how organizations represent, present, and constitute their organizational climate and culture the attitudes, values and goals that characterize the organization and its members. Organizations seek people who can follow and give instructions, accurately listen, provide useful feedback, get along with coworkers and customers, network, provide serviceable information, work well in teams, and creatively and critically solve problems and present ideas in an understandable manner. Communication is the lifeblood of any organization (Rana, 2013). If the communication breaks down, the organizational performance will be affected. Poor communication at the workplace is believed to be one of the top reasons why there are conflicts in organization. Poor communication or when the communication is neglected, people tend to be cynical and lose their trust and respect towards the organization and the leaders (Rana, 2013).

\section{Causes of Conflict in Organizations}

1. Communication issues

2. Organizational structure

3. Authority Responsibility Relationship

4. Contradicting personalities

5. Frustration and Stress

6. Competition

7. Dependency / Task interrelatedness

8. Incompatible goals/ Interdepartmental conflicting goal 
9. Conflict emanating from change

10. Corporate incivility

Communication Issues: For communication to take place, there must be a message to be passed across, there must be a sender, there must be a receiver and there must be feedback. When any of these communication channels is breached, then a gap occurs which causes communication setback and feedback is distorted. A simple instance like a manager reassigning a worker's task to his/her colleague, but failing to mention it to the concerned worker, or communicating his intentions to the worker before assigning the task, might lead to the employee harbouring negative perception about the manager or the co-worker. Repetitive occurrences of this nature in the future might lead to the employee's poor organizational conduct as a whole or towards the manager and might lead to serious organizational conflicts.

Organizational Structure: The structure wherein an organization is formed plays a very determining role in the conflict area. A simple example can be observed in the fact that in case of a matrix-structured company, decisional conflicts are almost built-in, as it is specified in the structure itself that an employee should report to two bosses (Gelfand et al, 2012). This type of a structure will almost always lead to confusion as the company is segmented into smaller parts, always having two opinions on one issue.

Authority Responsibility Relationship: The design of authority in the organizational structure determines the chances of arising of a conflict. An ill-defined authorityresponsibility relationship will definitely lead to a conflict. The lack of consistency in work is observed when such authority-responsibility relationships are not properly or rather clearly defined. Communication problems creep in and crack open wedges of conflict. Intergroup conflicts are usual results of such weak organizational structures (Sonnentag, Unger \& Nägel, 2013).

Contradicting Personalities: Employees come to work from different ethnic backgrounds, having had different experiences and harbour a different and individualistic mind set, thus forming a unique character of each to understand. In the case when one worker fails to understand the other in certain areas or maybe in areas relating to the area of the work assigned to them, conflicts take place (Deyoe \& Fox, 2012).

Frustration and Stress: Conflict arises in situations where the parties involved are too stressed out or frustrated with their own work. Stressed out people are more likely to start a quarrel with a little spark or can transfer aggression when stressed or frustrated.

Competition: So many things can cause competition in the work place, ranging from things that fall in the purview of work and things that are not even work related. Competition that falls in the purview of work may include trying to be the best among colleagues, or trying to get the best grade during appraisal. While those not related to work includes, competing in dressing, mostly among female employees, car competition etc. All of these can bring about conflict.

Dependency/ Task interrelatedness: When the task assigned to a department is dependent on the output of another department, then there is bound to be conflict. For example Cocacola Company, the department making the soft drink is at the mercy of the department producing sugar, because if the department producing sugar delays in the production, it will affect 
automatically the product output which may lead to conflict between the two departments in case there is a target to be met.

Incompatible Goals/ Interdepartmental Conflicting goals: In an attempt to reach the goals by each department, they may end up stepping on each other's toes just to meet their targets.

Conflict emanating from change: Change is the only constant thing and inevitable, but human beings are always averse to change. At the introduction of any change, there is bound to be rejection and crisis/conflict.

Corporate incivility: This could also lead to conflict in an organization. (John-Eke and Gabriel 2019), defined corporate incivility as impolite act meted out to employees by organizations or their agents; the instances include organizations nonchalant responds to sexual harassment report, discriminating practices of the organization; such as religious, sex, marital and ethnic discrimination are so glaring, and insensitivity of the organization to the plight of the employee.

\section{Types of Organizational Conflict}

1. Relationship conflict

2. Task conflict

3. Process conflict

4. Personal conflict

5. Intergroup conflict

6. Intragroup conflict

Relationship conflict: This type of conflict may arise from the interpersonal tension that exists between the employees of the concerned organization. These conflicts are concerned intrinsically with the persons. They do not concern the project or the assignment at hand.

Task conflict: These conflicts arise from the discordance that exists among the employees regarding the nature of the particular job at hand. These conflicts generally involve the members of the organization and the management of the concerned organization (de Wit, Jehn \& Scheepers, 2013).

Conflict of process: This conflict arises among the members of the same team. These conflicts arise from the differences in the opinions of the members regarding the ways in which the task should be completed.

Personal conflict: Personal conflicts refer to the ones that exist between two members of the organization. These conflicts arise due to the mutual dislike that exists between the workers.Lamb as cited in Tabitha and Florence (2019), referred to personal conflict as "man against self" conflict, in which such individual state of mind is largely dictated by circumstances within or around him/her. Such as anger, addiction, depression, frustration, confusion, this could result in aggression. It could be a conflict of values, of priorities in which man continues to battle or contend with his mind and habits leading to difficulties in deciding on a goal.

Intergroup conflict: intergroup conflicts, as the name suggests, refer to the conflicts that may arise due to the differences in the opinions between members of different groups that work within the same organization, while trying to meet their targets. This is a common occurrence at workplace scenarios where one group of workers might find themselves at a 
face-to-face junction with another group. This happens when, in order to perform one of their tasks, one group creates or rather obstructs the workflow of another group. This might be very damaging to the organization body as a whole if escalated. Thus, such a problem needs to be resolved as soon as it arises (Kerzner, 2013).

Intragroup conflict: Intragroup conflicts refer to the conflicts between the members of the same work group. These differences may arise from the lack of resources, liberty of the leader of the team and leadership method used by the leader, allocation of duties etc. (Babatunde, 2013).

\section{Effects of Conflict on the organization:}

1. When communication fail between management and employee, achieving the goal of the organization becomes difficult. This also leads to employee clamouring to be unionised so that their voice can be heard.

2. Conflict caused by diversity in Age, gender, academic background, religion etc. of a truth will go a long way to place an organization ahead of her competitors, but when not well managed, it can lead to low productivity, absenteeism, labour turnover, low morale etc.

3. Poor organizational structure may lead to employee doing things they want, just because they were not carried along in setting the objectives. That is why organization that make use of management by objective (MBO) are often more productive because, employees are part of the objectives set, they are also made to contribute to how these objectives are to be achieved. Other effects include:

4. Withdrawal: Parties involved in a conflict may tend to withdraw by behaving as if the conflict never happened. This will lead to anger and resentment, which may lead to a bigger conflict in the future.

5. When conflicts are well managed and both parties shift ground a bit for one another, not having anyone winning and the other party loosing, then both parties involved walk away from the conflict a better person, not damaging anyone's ego or selfesteem. In this situation, the parties involved in the conflict has known themselves better and each person's like and dislike, this will help the organization move faster and with speed in the future because the employee now understands one another the more.

Concepts that affect human relationships may include:

1. Anger

2. Apology

3. Trust and Distrust

4. Tolerance

5. Respect and Disrespect

Anger: The term anger has multiple meanings in everyday language. People refer to anger as an experience or feeling, a set of physiological reactions, an attitude toward others, a drive leading to aggression, or an overt assault upon some target. In social psychology, anger refers to a particular set of feelings. The feelings usually labelled as "anger" range in intensity from being irritated or annoyed to being furious or enraged. These feelings stem, to a large degree, from the internal physiological reactions and involuntary emotional expressions produced by an offense or mistreatment. Anger has been variously defined by psychologists, philosophers, and scholars. However, two issues are common among them all: 
1. The principal anger factors includes threats, frustrations, and obstacles in the way to the personal goals.

2. The aim of the anger is usually defence, fight, or destruction. There is no consensus about an accurate definition of anger and the concept has been used in different meanings in common language. In fact, anger is an emotion, which could be said in short, that ends in aggression. Anger is an affective emotional state which ranges from mild irritation to savage outrage and often shows up when the way to achieving goals or satisfying needs are blocked.

Apology:As part of the effort to contain the size and frequency of Conflict, many has adopted the laws of Apology. An apology has to be heart felt and reflect true remorse for past actions or the hurt caused. After apology, comes forgiveness, because without forgiveness, the parties involved in the conflict remain locked in the value system that produced the conflict.

Trust and Distrust:Trust has been defined as a willingness to become vulnerable to a trustee after having considered characteristics of that trustee. Research has focused on distrust, especially in this context. Distrust is defined as the unwillingness to become vulnerable to a trustee having considered characteristics of that trustee. Others argue that trust and distrust are distinct constructs that coexist. Lewicki et al. [20, p. 444] state that "high distrust is not the same thing as low trust" and McKnight et al. [24 p. 40] contend "distrust is the distinct opposite of trust." Trust focuses on more positive emotional reactions (hope, confidence and assurance) towards another and hence is positive. Distrust is based on more negative emotions (suspicion, wariness and fear) and hence is negative.

Trust issues can cause conflict within an organization when a person is too suspicious, this type of individual will refuse to trust anyone, which has its advantages and also it shortcomings.

Tolerance:Tolerance is the ability of an individual to come to reality with the fact that diversity exist in an organization, and the ability to accept others and live in peace, despite your differences. When we tolerate one another within groups, it helps us also to relate with other employees in other groups thereby limiting conflict and speedy actualization of organizational goals.

Respect and Disrespect: Respect is an unassuming resounding force, the stuff that equity and justice is made of. It means being treated with consideration and esteem and willingness to treat others in the same way. Respect plays an important role in a number of ways in conflict resolution;

1. Respect helps to build trust with others.

2. Respect allows one to build relationship.

3. According respect can make a major difference in settling conflict even if the conflict had occurred.

4. Respecting one another can lead to a positive change in the organization's environment.

Conflict Management: The focus of every organization in the society is to create a very conducive environment where employees can carry out their duties effectively without any 
negative influence that could hinder the achievement of individual and organizational goals. Nevertheless, conflict in organizations has become unavoidable because employees contend for authority, position, recognition, limited resources etc., No wonder Bercovitch (2011), posits that conflict is inevitable part of living because it is connected to states of scarce resources, division of functions, power relations and role differentiation. These contentions most times lead to conflict which sometimes turns out to be either dysfunctional or functional to the organizational effectiveness. Uchendu, Anijaobi and Odigwe (2013), argued that since conflict is unavoidable in organizations, its management determines whether it will produce positive or negative effect on the organization. Five conflict management styles that can be followed effectively to obtain a solution are enlisted below.

Avoidance or Withdrawal: Albanese (1998) posits that an avoiding style may reflect the failure to address important issues and a tendency to remain neutral when there is a need to take a position and therefore, of no value as a model of managing conflict.The individual tries to ignore the conflict passively instead of actually resolving it. He stays neutral in order to avoid the conflict entirely. Avoidance does not address the root causes of a conflict, rather, it is a way of postponing the issue, which will allow the conflict to degenerate into something more complex.

Accommodation or smoothing: This style portrays low position on assertiveness and high consideration for cooperativeness. Accordingly Albanese (1998)posits that a person who uses an accommodating style as the primary approach to conflict management may be showing too little concern for his personal goals. In this style, some level of unassertiveness and corporation is observed, it is a more submissive approach. The individual gives in passively to other party in order to resolve the conflict. They smoothen over the differences in mentality to preserve harmony. This method sometimes defines precedence and does not completely involve the participants as one gives in, though this resolves the situation and enhances the ego of the other party (Ellis \&Abbott 2012)

Compromise: The style involves considering expediency above principle as regards seeking short term solutions at the expense of long term objectives. The approach enables each party in conflict to share in some degree of winning and losing position. Bargaining is involved in this case, which takes into account the interests of each party so as to create a win-win situation. A give-and-take policy is applied in this style, keeping in mind what is acceptable to each party. Hence, in this case a win-win scenario is created thus satisfying both the parties involved in the conflict. This may lead to everyone feeling like a dead end in some situations though this shows good will and creates friendship (Sudha \& Khan, 2013

Competitive or authoritative: The approach involves high assertiveness and low competitiveness. The style is essentially power oriented and approaches conflict in terms of a win-lose strategy. On the negative side, according to Albanese (1998) a competitor may suppress, intimidate or coerce the other parties to a conflict. In this case, one of the two parties tries to resolve the conflict via aggressive behaviour or by force or authoritative influence. This style usually results in a less satisfied party and a victorious one. The victor usually obtains gains. This style, on a negative view, establishes battleground for the next conflict and gives rise to a series of conflicts. It may also cause in loss or withdrawal of important parties from the organization (Collewaert \& Fassin, 2013).

Collaboration: This is the most acceptable style of conflict resolving. In this case, the parties jointly try to resolve the problems with the most optimal solution acceptable to all the parties, 
although this creates an 'everyone' wins scenario this is usually very hard to achieve at all times. In addition to these styles, good inter personal skills, self-awareness, empathy, sympathy, confidence, clarity in conversation and other such qualities are required. There is a high chance of resolving conflict if all these qualities are kept in mind whenever a conflict surfaces (Nielsen \&Einarsen, 2012).

Within the field of communication, three models of organizational conflict management have dominated (Putnam 2006). First, the integrative and distributive negotiation model, which is based on Walton and McKersie's (1965) work on labour negotiations, examines formal approaches to conflict management. Second, the mediation competency model which refers to third party interventions in conflicts. Finally, the dual concern model which focuses on informal, individual level conflict management in organizations.

\section{Conclusion:}

The differences of opinions that we can have in the relationships between the people drag us into conflicting environment. Conflict is an ever present feature at each organizational levels, when conflict is well managed, it is productive, relevant and creative. The solution authority of the conflicts is the manager. It is the primary duty of the manager to enable workers to work harmonizingly around the common values. By examining the conflicting parties, the subject of the conflict, the sources and reasons of the conflict, the manager determines the most appropriate method and puts it into practice. Sometimes more than one method may be put into practice suddenly or in an order. Finding out the fastest, the most effective and correct solution is the managerial skills of the manager. However, it is important for the manager to ensure proper communication within the organization, because conflict is created, maintained and changed through communicative action. The fact that the manager is neutral and provides a convenience for the decisions he makes the acceptance of the parties about these decisions. 


\section{References}

Ademowo, A.J. (2016). Viewpoints on conflict and peace management: Tic-Tac-Toe consulting. ISBN: 978-978-31064-4-0.

Adu-Oppong, A. A., \&Agyin-Birikorang, E. (2014). Communication in the workplace:

Guidelines for improving effectiveness. Global Journal of Commerce \& Management Perspective, 3(5), 208-213.

Albanese, R. (1998). Managing: Towards accountability for performance. New York: Richard D. Irwin Inc.

Berkowitz, L. (1999). Anger. In T. Dalgleish\& M. J. Power (Eds.), Handbook of cognition and emotion (pp. 411-428). New York: Wiley.

Bercovitch, J. (2011). Conflict and conflict management in Organisations: A Framework for analysis. Retrieved: http://www.aspheramedia.com/v2/ 20/01/2021.

Collewaert, V., \&Fassin, Y. (2013). Conflicts between entrepreneurs and investors: the impact of perceived unethical behavior. Small Business Economics, 40(3), 635-649.

De Wit, F. R., Jehn, K. A., \&Scheepers, D. (2013). Task conflict, information processing, and decision-making: The damaging effect of relationship conflict. Organizational Behavior and Human Decision Processes, 122(2), 177-189.

Deyoe, R. H., \& Fox, T. L. (2012). Identifying strategies to minimize workplace conflict due to generational differences. Journal of Behavioral Studies in Business, 5, 1.

Ellis, P., \& Abbott, J. (2012). Strategies for managing conflict within the team. British Journal of Cardiac Nursing, 7(3), 138-140.

Gelfand, M.J., Leslie, L.M., Keller,K.,\& de Dreu, C.(2012). Conflict cultures in organizations: How leaders shape conflict cultures and their organizational-level consequences. Journal of Applied Psychology, 97(6), 1131.

Horton, K. E., Bayerl, P. S., \& Jacobs, G. (2014). Identity conflicts at work: An integrative framework. Journal of Organizational Behaviour, 35(S1).

John-Eke, E. C., \& Gabriel, J. M. O. (2019). Corporate incivility and employee engagement. West African Journal of Business, 13(1), 1595-3750.

Kerzner, H. (2013). Project management: a systems approach to planning, scheduling, and controlling. John Wiley \& Sons.

Lewicki, R., McAllister, D.J., and Bies, R., Trust and distrust: new relationships and realities. Academy of Management Review, 23(3) (1998). pp. 438-458.

Lumineau, F., Eckerd, S., \& Handley, S. (2015). Interorganizational conflicts: Research overview, challenges, and opportunities. Journal of Strategic Contracting and Negotiation, 1(1), 42-64. 
McKnight, H., Choudhury, V., and Kacmar, C. (2002). "Developing and validating trust measures for ecommerce: an integrative typology", Information Systems Research (13) 3, pp. 334-359.

McKnight, D. H. and N. L. Chervany. 2001. "Trust and distrust definitions: One bite at a time”. In: Trust in Cyber-Societies. Ed. by R. Falcone, M. Singh, and Y. H. Tan. Berlin Heidelberg, German: Springer. 27-54.

McKnight, D. H., L. L. Cummings, and N. L. Chervany. 1998. "Initial trust formation in new organizational relationships”. Academy of Management Review. 23: 473-490.

Mikkelsen, E. N., \& Clegg, S. (2017). Conceptions of Conflict in Organizational Conflict Research: Toward Critical Reflexivity. Journal of Management Inquiry, 1056492617716774.

Moore, C. W. (2014). The mediation process: Practical strategies for resolving conflict. John Wiley \& Sons.

Nain, A. S. M. (2017). Conflict perspectives in analysing and understanding organizational behaviour. JurnalKemanusiaan, 2(2).

Nielsen, M. B., \&Einarsen, S. (2012). Outcomes of exposure to workplace bullying: A metaanalytic review. Work \& Stress, 26(4), 309-332.

Prause, D., \&Mujtaba, B. G. (2015). Conflict management practices for diverse workplaces. Journal of Business Studies Quarterly, 6(3), 13.

Putnam LL.2006. Productive conflict: negotiation as implicit coordination. Int. J. Confl. Manag. 5:284-98

Rana, R. (2013). Effective Communication in a Diverse Workplace. International Journal of Enhanced Research in Management and Computer Applications, 2(2).

Ruben, B.D. (1978) 'Communication and Conflict: A System-theoretic Perspective', The Quarterly Journal of Speech, Vol. 64, pp. 202-210.

Russ, T. L. (2013). The relationship between Theory X/Y: assumptions and communication apprehension. Leadership \& Organization Development Journal, 34(3), 238-249

Sonnentag, S., Unger, D., \&Nägel, I. J. (2013). Workplace conflict and employee well-being: The moderating role of detachment from work during offjob time. International Journal of Conflict Management, 24(2), 166-183.

Sudha, K. S., \& Khan, W. (2013). Personality and motivational traits as correlates of workplace deviance among public

Tabitha, M., \& Florence, G. (2019). Conflicts and conflict management in modern organizations-A pre-conflict resolution environment approach. International Journal of Scientific and Research Publications, 9(8), 2250-3153.

Uchendu, C., Anijaobi, F., \&Odigwe, F. (2013). Conflict management and organizational performance in secondary schools in Cross Rivers State. Nigeria Research Journal in Organizational Psychology and Educational Studies, 2(2), 67-71. 
Journal DOI: www.doi.org/10.46654/RJMP

Article DOI: www.doi.org/10.46654/RJMP.15526

Walton RE, McKersie RB. 1965. A Behavioral Theory of Labor Negotiations. New York: McGraw-Hill 